of Judge Doe, of New Hampshire, delivered in 1869. He savs. "At presentprecedents require the jury to be instructed by experts in new medical theories, and by judges in old medical theories." In doing this " the legal profession were invading the province of medicine, and attempting to install old exploded medical theories in the place of facts established in the progress of scientific knowledge. That cannot be a fact in law which is not a fact in science; that canuot be health in law which is disease in fact; and it is unfortunate thatcourts should maintain a contest with science and the laws of nature upon a question of fact, which is within the province of science and outside the domain of law." He further remarks, "If the tests of insanity are matters of law, the practice of allowing experts to testify what they are should be discontinued; if they are matters of fact, the judge should no longer testify without being sworn as a witness, and showing himself qualified to testify as an expert." This, to my non-legal mind, seems to be good, sound common sense. If it were not admitted that there are certain facts with regard to insanity cognisable by medical men none of the persons found in our asylums ought to be there. The law in these cases admits that there are facts of insanity of which medical men are competent judges, but in criminal cases, for some reason not clearly defined, the law utterly repudiates medical testimony. In all other cases the testimony of experts is accepted and acted upon; why not, therefore, in the case of insanity? Another anomaly also present in these cases is this, the public are fully acquainted with the evidence that convicted Sweetland, but no one knows the grounds for the alteration of the sentence. The grounds for the reprieve should become as public as those for the conviction; and why should not the evidence on which the reprieve is granted have been allowed on the trial? Apologising for having taken up so much of your valuable space,

I am, Sir, yours faithfully,

H. AUBRey Husband, M.B. Lecturer on Medical Jurisprudence, Edinburgh

July 19th, 1880 School of Medicine.

\section{CHIAN TURPENTINE IN CANCER.}

\section{To the Editor of THE LANCET.}

SIR, - In so horrible a disease as cancer of the female renital organs, and one in which we are compelled to admit that we are powerless to do more than palliate suffering, I quite agree with your correspondent Mr. Hickinbotham (evde THE LANCET of June 19th), that it is our duty to adopt any treatment which is supported by high authority, and especially by so high an authority as Professor Clay. It is, I think, equally our duty to report the result of such treatment fairly and without prejudice, whatever those results may be, and I therefore briefly give you my notes of a case in which $I$ have employed this remedy.

Mrs. H_- aged sixty-two, a widow, who has never borne children, complained to me in February of the present year of passing blood with the urine, pains in the back and legs, and great weakness. I thought her suffering from disease of kidneys and consequent hæmaturia, but on visiting her at home I found the urine perfectly clear, with one or two smal coagula at the bottom of the vessel. I then made a vaginal examination, and found a cancerous growth, which bled freely on the slightest tonch, extending from the back of the meatus upwards for about two inches in the anterior wall of the vagina; above this the wall appeared healthy, but somewhat hard and thickened; the os uteri was freely movable, arud did not appear to be involved. Continuing under treat ment she had occasional attacks of sharp hæmorrhage, which yielded to rest and astringent injections.

(in the appearance of Professor Clay's article I thought this a typical case for treatment, and accordingly, having first examined her again, and found the disease slowly but steadily progressing, commenced the Chian turpentine in the form of emulsion as advised by Professor Clay, explaining to the patient that it was a new mode of treatment which had alread 8 produced highly successful results, and thus, by instilling great hope into her mind, securing her anxious co-operation with me in the treatment. She commenced taking the turpentine on April 18th, and continued it with out the intermission of a single dose to June 20th, when it was discontinued. The effect at first appeared to be that of decidedly relieving the pain and enabling her to move about with much more comfort, though whether this was due to renewed hope or the action of the remedy is a question. After a month's trial the medicine seemed to create some loathing, but she determined to persevere. She continued it till June 21st, when a severe attack of hæmorrhage compelled me to resort to other treatment, and at the request of her relatives Dr. Coates saw her with me on the 25 th inst. The condition we then found was as follows:- The front of the vagina was converted into a solid hard mass, which had extended in all directions, contracting the passage considerably; the os uteri fixed and hard; the inguinal glands enlarged, and, in fact, a more rapid development of the disease than I was prepared to expect.

My conviction (with which I believe Dr. Coates fully coincides) is that this remedy had utterly failed either for good or evil to influence the course of the disease.

I have tried it in two other cases, one of epithelioma of the lip, the other of cancer of the pylorus, but in both cases without the slightest effect, but have preferred to publish the above case as being one in which no other treatment was used, and in which it was perseveringly and unintermittingly followed up.

I may add that the emulsion was dispensed by Messrs. Davies and Hughes, whose reputation as dispensing chemists ranks deservedly high in this city.

I remain, Sir, yours, \&c.,

Green Park, Bath. RoBERT BIGGS, M.R.C.S.E., L.S.A.

\section{To the Editor of THE LANCET.}

SIR, - The two following cases have recently been treated by the above method:-

Case 1 was a woman, aged forty-eight, with cancer of womb of six months' duration. Dr. Clay's etherial solution of turpentine with sulphur was used. Treatment commenced on April 17th, 1880, and continued to the present time ; patient has gradually emaciated; pain unrelieved; disease has continued to advance, notwithstanding that the medicine has been well tolerated by the stomach. Case 2 was one of cancer of breast in a woman aged sixty-five. The breast had been totally destroyed by the disease-a large circular ulcer, with hard everted edges, situated where the breast had been. Treatment commenced same date as Case 1, and continued till patient's death, on July 3rd, 1880 . Although the patient died in this instance, the base and edges of the ulcer became softer and the ulcer smaller in diameter. Although there was some affection of the axillary glands when the treatment was commenced it did not spread much. What the result would have been if treated earlier it is impossible to say.

$$
\begin{gathered}
\text { I am, Sir, yours faithfully, } \\
\text { Workington, July 17th, } 1880 .
\end{gathered}
$$

\section{EDINBURGH}

\section{(From a Correspondent.)}

AT the graduation ceremonial on Monday 158 medical candidates appeared for degrees ; of these 28 received that of M.D.; 124 M.B. and C.M. ; and 6 M.B. alone. The following gentlemen obtained gold medals for their theses, Drs. De Burgh Birch, Allan Gray, David Berry Hart, and J. Francis Sutherland. The Ettles Prize has been awarded to T. P. Anderson Stewart, who obtained the highest number of marks during the course of his professional examinations; the Beaney Prize to $\mathrm{H}$. W. Dobie, who stood highest in Anatomy, Surgery, and Clinical Surgery; the Wightman Prize to R. F. Rand, for the best essay on clinical cases, and the Syme Surgical Fellowship to Dr. David Berry Hart. Mr. W. L. Good win obtained the Hope Prize in chemistry. Professor Turner introduced Dr. William Roberts, of Owens College, Manchester, to receive the Cameron Prize for his researches in the Digestive Ferments, \&c. Professor Rutherford, in delivering the valedictory address took up the subject of Medical Examinations and Reform. He objected strongly to the English one-portal scheme, indicated the leading part played by Scottish Universities in medical education, and surrested that a few simple reforms would act more beneficially than certain pro. posed radical changes. Professor Maclagan presided at the Graduates' dinner in the evening. 